\title{
试论海南省蝴蝶保护与可持续性利用的关系
}

\author{
顾茂林 \\ (中国林业科学研究院热带林业研究所, 广州 510520)
}

\begin{abstract}
摘要 : 根据世界自然保护联盟 (IUCN) 1994 年前制订的《IUCN 红色名录》和 1994 年 IUCN 理事会第 40 次会议上通 过的《世界物种红色名录濒危等级》(IUCN Red List Catagories), 针对我国 1989 年颁布的《国家重点保护野生动物 保护名录》和 2000 年国家林业局颁布的《国家保护的有益或者有重要经济、科学价值的陆生野生动物名录》中有关 蝴蝶的部分, 简述制订时的历史背景, 就其中涉及海南分布的蝴蝶保护种划分的科学依据进行了探讨; 建议今后蝴 蝶保护名录修订时应将栖息地的保护状况列为评估濒危状况的首要依据, 使保护名录更附合客观事实并有利于保 护的可操作性; 提出保护生物资源的最终目的是在条件成熟时对它们进行利用, 如果可持续性利用的生物资源不 加以利用, 就是对资源的浪费; 在利用中需引入高新技术、开拓创新, 以提高利用效益, 进而提升资源保护的管理水 平。
\end{abstract}

关键词: 蝴蝶栖息地, 保护名录, 红色名录, 濒危等级, 优势种群

中图分类号:Q16 文献标识码：A 文章编号 : 1005-0094(2003)01-0086-05

\section{On the relationship between protection and sustainable utilization of butterflies in Hainan Province}

GU Mao-Bin

Research Institute of Tropical Forestry, Chinese Academy of Forestry, Guangzhou 510520

\begin{abstract}
Based on the IUCN ( the World Conservation Union) Red List and IUCN Red List Categories , the historical background of the butterfly species listed in the Chinese List of Key Protected Wildlife of National Importance (1989) and the Terrestrial Wild Animal Species List of High Economic and Scientific Val$u e$ is briefly introduced. The basis for definition of protected butterfly species that are naturally distributed in Hainan is evaluated. We suggest that habitat status should be the primary criterion for identifying threatened butterfly species, which differentiates them from the mechanism of endangerment of many amniotes and other arthropods, and makes protection operations more practical. The objective of formulating these lists of threatened species is to guide rational utilization of butterfly resources. Sustainable bio-resources should be available for rational use to serve human needs. Evaluation of habitat status should be based on both protection and utilization perspectives. Butterfly raising and near-natural-forestry with advanced technology should be encouraged to simultaneously develop the butterfly industry, to improve resource utilization efficiency and consequently enhance resource protection management.
\end{abstract}

Key words : butterfly, habitat, Red List, threatened level , primary population

\section{1 前言}

世界自然保护联盟 ( IUCN) 在 20 世纪 70 年代 制订了《IUCN 红皮书》(陈灵芝，1993），此红皮书制 订以后在国际上被广泛采纳并作为制订各国保护名
录的参考。1989 年, 我国公布了《国家重点保护野 生动物保护名录》;1994 年 IUCN 理事会第 40 次会 议上通过了修正后的红皮书;同年我国成立了环境 与资源保护委员会; 2000 年国家林业局颁布了《国 家保护的有益或者有重要经济、科学价值的陆生野 
生动物名录》。

发达国家如英国、法国的蝴蝶产业已有200多 年的历史，发展中国家如巴西、秘鲁也有 100 多年的 历史，而我国由于历史的原因 蝴蝶资源没有得到应 有的利用。由于活动于树冠的昆虫调查非常困难， 有些种类可能今后很长一段时间内不易摸清。因 此，以前制定的保护名录存在不够准确的情况是正 常的。对第二次公布的野生动物保护名录中海南有 分布的蝴蝶种群，笔者参考了 IUCN 1994 年前后两 版红皮书中确定的濒危等级逐一加以评估, 试图以 此引起有关方面的注意,使我国蝴蝶保护名录与保 护级别修订时能比较客观地反映自然界的实际情况 并与《IUCN 红皮书》相接轨，既可提高蝴蝶资源保 护的可操作性，也有利于对蝴蝶资源的可持续性利 用。

\section{2 我国两次公布的海南有分布的蝴蝶保护 种的评估依据}

我国对昆虫的调查与保护研究, 由于历史的原 因起步较晚，虽然 20 世纪 80 年代开展了一些调查， 但远未普及和深入，对蝴蝶等昆虫的资源与濒危状 况不太清楚。为配合野生动物保护执法,一些学者 根据自己的了解呈报了保护名录。当时认定金斑喙 凤蝶 (Teinopalpus aureus) 仅在广东和福建有采集记 录, 为中国特有, 因此 1989 年公布的蝴蝶保护名录 中, 海南只有金斑潒凤蝶 1 种, 并定为一级保护的野 生动物。

80 年代后, 随着昆虫区系调查的深入,金斑㖨 凤蝶在其他地区陆续被发现, 到目前为止, 已知金斑 喙凤蝶广泛分布于浙江、福建、江西、湖南、广东、广 西、云南 (吴云,1999) 、海南(顾茂彬, 陈佩珍,1997) 等省;国外分布于越南、老挝（Igarashi，2001），并非 中国特有种。金斑潒凤蝶栖息地为海拔 $1000 \mathrm{~m}$ 左 右的热带山地雨林以及中亚热带、南亚热带原始阔 叶林，寄主为种类较多的木兰科 (Magnoliaceae) 植物 (黄邦㑆,2001; ;garashi，2001)，海南各大林区均有 分布。在天然林已停止采伐的今天, 其种群的生存 是安全的。因该种无下飞习性，所以不容易采到，但 这不等于濒危或稀少。例如设在海拔 $1000 \mathrm{~m}$ 处的 广东某保护区的 1 个保护站的员工,曾用扫把打到 雌性金斑嗄凤蝶，并在该地带的草丛中拾到雄性死 虫, 也有其他员工拾到过死虫。能够在天然林中多
次拾到死虫, 虽然目前无法对它按 IUCN 的有关规 定进行定量分析,但可推测其种群密度并不低。根 据 IUCN 1994 年以前濒危等级和保护级别的有关规 定 (袁德成,2001;解炎，汪松，1995），我国特产、稀 有或濒于灭绝的野生动物才被列为一级保护动物; 按 1994 年版《红色名录》等级( WCMC ,1994;SSC/ IUCN ,1994) 系统来套, 能定为 极危”或濒危”等 级的动物才被列为一级保护。据此, 将金斑喙凤蝶 定为一级保护显然是欠妥的，作为保护种也值得商 整,可列入红色名录。

在 2000 年我国第二次公布的野生动物保护名 录中海南有 17 种蝴蝶，分别是金斑嚎凤蝶、裳凤蝶 污斑亚种( Troides helena spilotia)、海南裳风蝶( Troides sp. ) ( 未定种)、金裳凤蝶 (Troides aeacus)、暖曙 凤蝶 (Atrophaneura aidonea)、瓦暖曙凤蝶海南亚种 (Atrophaneura varuna astorion)、玛暖曙风蝶海南亚 种( Atrophaneura nox hainanesis)、锤尾凤蝶（Losaria coon)、燕凤蝶 ( Lanproptera curia) 、绿带燕凤蝶 (Lanproptera meges)、箭环蝶 (Stichophthalma howgua)、双 星箭环蝶 (Stichophthalma neumogenni)、枯叶蛱蝶 (Kallima inachus)、豹眼蝶 (Nosea hainanensis)、黑眼 蝶 (Ethope henrici)、虎灰蝶 (Yamamotozephyrus kwangtungensis)、森下交脉环蝶 (Amathuxidia morish$i t i$ ) 等共 17 种。其中森下交脉环蝶为新纪录属新 种，在海南只分布于尖峰岭林区，目前只发现于热带 半落叶季雨林中, 因该植被区域很窄, 又地处低海 拔，人为活动频繁，林分破坏严重，应列为濒危”或 “易危” 级别; 其余 16 种都为热带常绿季雨林、热带 山地雨林的常见种。只要这些植被类型的生态环境 不被破坏, 就不存在 危” 的问题, 所以不宜列入保 护名录。

\section{3 资源保护、保护物种与资源利用的关系}

\section{1 资源保护、保护名录与红色名录}

《全球生物多样性策略》指出 “: 保持物种的最 佳途径是保持它们的生境” (WRI \& IUCN \& UNEP , 1993 )。蝴蝶保护名录的确定应依据其资源和栖息 地的保护状况, 这是蝴蝶资源能否得到保护的最核 心的问题, 也是评估其濒危和保护级别最重要的依 据。而恰恰是这一点在实践中容易被忽视。根据这 一原则, 若某种蝴蝶分布范围广, 栖息地为多种森林 植被类型，即使因形态美丽等原因捕捉量较大，也可 
不列入保护名录和红色名录。例如红锯蛱蝶 (Cethosia biblis) 和短尾翠凤蝶 (Papilio doddsi), 虽 然我国只在海南岛有分布，但因其栖息地为热带天 然林, 其种群有相当的密度, 故不会因采捕等原因受 胁迫，可不列入保护名录和红色名录。

要明确红色名录和保护名录的侧重点不同以及 它们之间的联系: 红色名录编制较详细, 种类较多， 侧重于科学功能、资源濒危评估功能和潜在经济价 值的预测; 保护名录是在红色名录的基础上制订的, 它强调保护的可操作性、管理的权威性和法律的严 肃性(袁德成,2001)。因此, 对保护名录的制定应 高度重视、严肃认真，参与保护名录制定的专家不仅 要有较深的专业知识 (主要指从事昆虫生物学和生 态学研究的经验) 外, 还应对重点保护物种的遴选 和定级原则有所了解, 以便准确评估在保护好栖息 地的前提下，捕捉等人为因素能否对有关种群造成 濒危，以及目前状况下能否利用及利用的原则，还可 对蝴蝶商进行调研，了解相关信息。

\section{2 资源保护与利用}

要辩证地认识资源保护与利用的问题，一切不 利于开发的保护就失去保护的意义;同理，不加保护 的开发一定是不可持续的。因此，保护与利用的关 系不是两个完全对立的方面，只要正确处理就能起 到相互促进的作用。我国蝴蝶资源丰富的地区大多 为贫困山区,森林资源破坏严重是保护意识差和生 活水平低造成的。由于毁林烧山，很多珍贵的生物 资源在被人们发现或认识以前就从地球上消失了, 这是十分可惜的。所以，我们既要开展宣传教育工 作, 又要重视当地农民的实际利益，引导和鼓励他们 通过出售抓捕或饲养蝴蝶来改善生活。在此过程 中，让人们认识到若森林没有了, 就没有蝴蝶可捕可 养的朴素道理 增强不毁林、不破坏蝴蝶生存环境的 观念。在贫困地区只有发挥资源效益, 实现区域经 济的发展,才能在有效地保护资源的同时也维护贫 困人群的资源利益。小规模蝴蝶产业在南美、非洲 有报道，国内在云南西双版纳、海南尖峰岭也可见 到，但因缺乏统一管理、规模小、资源利用效益差，因 此破坏热带林的现象时有发生。所以，我们要开拓 新的思路, 有目的、有计划地引导民众，吸收高素质 的人才参与资源管理和利用。蝴蝶不仅具有观赏价 值，还有为植物传粉、食用(文礼章, 1998; 尤民生， 1997 )、药用和教育等多方面的价值, 有较高的经济
和社会效益。对某些种类进行人工养殖并在自然界 种植蝴蝶的寄主植物, 发展近自然林业, 可以保护蝴 蝶的栖息地增加它们在自然界的种群密度。

\section{4 资源利用的几个认识问题}

\section{1 对蝴蝶的生物学特性的了解}

媒体曾将一级保护的大熊猫与一级保护的蝴蝶 相提并论。大熊猫生命历程数十年,自然界或人工 繁殖一头很不容易; 而蝴蝶不仅个体小, 而且繁殖能 力强，年世代数多，如菜黄粉蝶 (Eurema blanda) 1 年 12 代(顾茂涁等,1991)、迁粉蝶 (Catopsilia pomona) 1 年可达 15 代（顾茂彬，1983），每头雌虫产卵从几 十粒到二百多粒不等( 顾茂涁, 陈佩珍,1987)。只 是自然界有生态平衡的调节机制, 蝴蝶从卵到成虫 的发育过程中, 大多被食物链中的天敌捕食（顾茂 彬, 1987) 淇次是成虫寿命短, 如海南蝴蝶成虫寿 命在 1 周左右, 交尾后雄蝶 $1 \sim 3$ 天死亡, 雌蝶接近 产完卵时死亡, 未经交尾的雄蝶和雌蝶寿命稍长。 因此只要蝴蝶的栖息地能够得到较好的保护，少量 利用不会构成对其种群的胁迫，而不利用却是对资 源的浪费。因此在评估蝴蝶保护种类及保护等级时 不宜与大、中型的鸟兽相提并论。树冠昆虫的种群 密度由其寄主多寡、寄主分布、天敌等自然法则决 定, 若某种昆虫的寄主植物在天然林中分布范围窄、 种群密度低,加上人为破坏使该植物过少或消失, 就 会导致某种昆虫的消失。我国约有昆虫 15 万种以 上（尤民生，1997）, 目前很多昆虫的寄主我们还不 了解，而林区(包括保护区) 盗伐木材的现象还存 在，因此保护栖息地是保护蝴蝶种群的关键。

4.2 捕蝶对种群濒危的影响

人为捕蝶对蝴蝶的胁迫作用, 是有争议的一个 问题。对于栖息于热带原始林的蝴蝶 (Erwin, 1983 ), 有些种我们目前还无法知道它的种群密度, 有的种甚至还未被发现。蝴蝶的生境极为复杂并经 历了千百年的自然选择，经受了食物短缺、疾病、天 敌捕食和各种恶劣天气的考验，它凭借的是栖息地 的生物多样性以及复杂食物网络所拥有的生态环境 的整体抗逆修复功能 (马克明, 2001)。由此可以得 出，生活在热带林中的蝴蝶，在停止天然林采伐的今 天, 有健康的生态系统存在, 其种群是安全的。目前 海南保护较好的热带林都划为保护区，不允许捕猎 包括蝴蝶在内的野生动物。捕蝶活动大多在次生林 
周边地带进行。笔者经过几十年的研究工作有如下 观点: 虽然从生态学方面来看捕蝶对蝴蝶是有一定 影响，但因为捕蝶范围较窄，未造成生态系统的群落 结构变化, 这种影响只限于种群密度的波动, 不会导 致种群的濒危。因为有大片热带天然林的存在，人 不可能在林中挥网捕蝶，对主要活动于十多米至数 十米高的树冠的蝴蝶，人不可能捕到，而只能在林中 小片空地、溪边、林缘等小范围内捕获那些吸水、取 食、交配和寻受寄主的属优势种群的少量个体 ( $90 \%$ 左右为雄性)。这种影响与恶劣天气( 台风 等) 相比而言, 小到可以忽略不计。而且昆虫种群 密度在自然界有自我调节潜能。例如海南尖峰岭在 $1995 \sim 2001$ 年都有人去收购蝴蝶，这些蝴蝶基本采 自林缘、水沟边。经对蝴蝶采集者调查，每年采捕的 蝴蝶以红授绿风蝶 (Pathysa nomius) 、斑凤蝶 (Chilasa clytia)、青斑蝶 (Tirumala limniace) 等 34 种为主。 上述种类在每年 $4 \sim 7$ 月份的晴天 $9.00 \sim 12.00$ 时， 可在林缘的植物上见到, 其年际间种群数量没有变 化, 只是某些种群的密度有变化。

\section{3 蝴蝶饲养与可持续利用}

国家鼓励对野生动物（包括蝴蝶）进行人工饲 养, 利用人工饲养的生物不会破坏生态环境, 是可持 续性的, 只有这种利用才能被认可和批准。饲养蝴 蝶的关键技术是:饲养地的生态环境应能满足所饲 养种类在生长发育过程中的要求:繁育室要有足够 大的空间，内部种植寄主植物和蜜源植物，有饮水及 防范天敌的设施。这些从技术层面看难度不大，但 我国目前还没有专业化饲养蝴蝶的企业, 其主要原 因是产品不能被市场所接受。因为我国蝴蝶产业还 未发育好, 需求总量少, 人工饲养的产品价格昂贵。 若饲养珍稀种类，还需到大山深处去选址发展，饲养 成本更是成倍增加; 加之产品发展空间有限, 饲养数 量增多后价格就会下降，饲养业必然面临困境而破 产。因此，对蝴蝶的饲养要突破以前仅限于室内的 概念，将蝴蝶饲养扩展到自然环境中去，发展近自然 林业。可选择交通方便的林缘地带设计营造有多种 蝴蝶寄主的混交林, 既增加了生物多样性, 又可将蝶 类幼虫的密度控制在经济阈值之内。这种增殖自然 界蝴蝶种群与种群密度的林业措施，既是蝴蝶资源 的保护与更新建设, 也是遵循生态学原理的科学管 理。例如次生林边缘规划一片由黄皮( Clausena lansium)、黄兰 (Michelia champaca)、鱼木 (Crataeva religiose)、木豆 (Cajanus flavus) 组成的混交林, 就可 为美凤蝶 (Papilio memnon)、玉带凤蝶 (Papilio polytes）、达摩凤蝶（Papilio demoleus）、统帅青凤蝶 (Graphium agamemnon)、木兰青凤蝶 (Graphium doson)、鹤顶粉蝶 (Hebomoia glaucippe)、灵奇尖粉蝶 (Appias lyncida)、镉黄迁粉蝶 (Catopsilia scylla) 等多 种蝴蝶营造繁殖基地, 如果林内再种上攀缘植物珠 龙果 (Passiflora foetida) 就增加了白带锯蛱蝶 (Cethosia cyane)、红锯蛱蝶 (Cethosia biblis)、斑珍蝶 (Aeraea violae)、文蛱蝶 (Vindula erota) 等的寄主植 物。

上述蝴蝶都是抗逆性、观赏性较强的乡土种类， 一般情况下这种开放式饲养都能获得成功。可见， 发展近自然林业不仅仅是蝴蝶资源可持续性利用的 需要,而且是环境建设和经济发展的需要。

\section{5 讨论与建议}

\section{1 修订我国蝴蝶保护名录}

我国蝴蝶保护名录应以《世界物种红色名录濒 危等级》为根据，尽快启动修订程序，参与修订的人 员要有较深的生态学理论基础或是蝴蝶生物学与生 态学研究的专家, 也就是说, 有关专家必须了解相关 蝴蝶的栖息地生境、生态分布、致危原因和掌握有效 保护的技术，这样保护名录才能正确定位。

\section{2 保护与利用}

1989 年我国首次公布了《国家重点保护野生动 物名录》,在此之前，鸟兽等大、中型野生动物被人 们大量捕猎后食用、药用或用其毛皮等，利用时间已 较长。野生动物保护名录的提出, 是在对这些资源 被过度利用的濒危状况比较了解的情况下作出的; 而我国蝴蝶的保护名录是在蝴蝶产业尚未形成以及 资源状况不十分清楚的情况下提出的，明确这一点 有助于理解我国两次提出蝴蝶保护名录的科学基 础。因此，一方面要对已列入的保护种进行调查; 另 外,修订保护名录时应认真参照世界自然保护联盟 制订的《IUCN 红色名录》和《世界物种红色名录濒 危等级》划分保护种类及其等级的标准。考虑到我 国蝴蝶资源研究与利用的滞后，保护区内的蝴蝶资 源已经得到保护以及人为捕捉不会对种群造成胁迫 的情况，有些资源状况不太清楚的种类可暂不列入 保护名录, 鼓励开发利用, 促进产业发展以解决贫困 山区农民的生活问题和热带林有效保护的问题。 


\section{3 发展生物多样性保护和利用的人力资源}

世界蝴蝶市场与前二三十年相比，已有了很大 不同，有关动物保护组织反对用蝴蝶制作的工艺品 进行贸易, 这有它积极的一面,但也不完全正确。对 可持续性利用的生物资源不加利用无异于浪费资 源, 不利于人类生存与发展, 也不利于人们生活质量 的提高。尤其象我国这样有 13 亿人口的大国，学校 用于生物课教学的标本还十分缺乏, 这不符合重视 基础教育的时代要求。因此, 将原始的生物资源转 化为教育资源, 市场潜力巨大、意义深远。目前蝴蝶 加工从业人员大多科技知识水平不高,市场上的某 些工艺品制作粗粘或不科学，有些还不如日本 20 世 纪 50 年代的产品; 某些人工蝴蝶园的设计缺乏对蝴 蝶生态学的了解, 效果很差。因此, 应在政策导向和 媒体宣传方面重视对蝴蝶资源的利用，培养专门人 才，加强对栖息地资源的管理、建立理论与实践相结 合的濒危物种的评估体系、建立信息系统和开展保 护生物多样性的基础研究与应用研究, 解决蝴蝶产 业化进程中保护与利用的关键技术问题。在提高工 艺品档次的同时,研究扩大蝴蝶资源利用范围,使 21 世纪我国蝴蝶产业与时俱进，使蝴蝶资源的可持 续性利用与社会经济协调发展 (封志明 2000)。

\section{4 建议与结语}

有关部门在划定保护种类和划分保护等级时， 应对脊椎动物与节肢动物有所区别。虽然同样是野 生动物，但它们之间在个体大小、寿命长短、繁殖能 力、濒危机制等方面差异很大，如老虎与昆虫类是不 能在同一层次上相比的。被列为濒危的蝴蝶物种, 应有明确的应急措施和负责单位，例如海南尖峰岭 的森下交脉环蝶，因为个体大，它的濒危不仅是环境 破坏或滥捕的问题,还有最小可生存种群 (MVP) 的 问题,需要制定保护计划，解决栖息地保护和遗传学 所面临的迫切问题。

因为笔者对热带林中的蝴蝶区系比较熟知，所 以本文只述及海南蝴蝶种群，对不熟悉地区的蝴蝶 种类不妄加评论。

\section{参考文献}

Chen L Z (陈灵芝), 1993. Biodiversity of China-Current Status and Protection Countermeasures. Science Press, Beijing ( in Chinese)

Erwin T L, 1983. Beetles and other insects of tropical canopies at Manaus, Brazil, sampled by insecticidal fogging. In: S L Sutton, T C Whitmore and A C Chadwick(eds.), Tropical Rain Forestry: Ecology and Management. Blackwell Scientific Publications, Oxford, 59 76

Feng Z M (封志明), 2000. Ideology of resource in the 20th century. Resources Science (资源科学)，22(5): 1 6 (in Chinese)

Gu M B (顾茂涁), 1983. Biology and control of Catopsilia pomona Fabricius. Acta Entomdogica Sinica (昆虫学报), 26 (2) : $172 \sim 178$ (in Chinese)

Gu M B (顾茂涁), 1987. Population variation of Catopsilia pomona in different habitat. Tropical Forestry Science and Technology (热带林业科技)，(4)：68７0 (in Chinese)

Gu M B (顾茂涁) and P Z Chen (陈佩珍), 1987. A preliminary study on Pnalanta phalantha Drary. Scientia Silvae Sinicae (林业科学), 23(1): 105 108 (in Chinese)

Gu M B (顾茂涁) and P Z Chen (陈佩珍), 1997. Butterflies in Hainan Island. China Forestry Publishing House, Beijing (in Chinese)

Gu M B (顾茂涁)，P Z Chen (陈佩珍) and C L W ang (王春 玲), 1991. A preliminary study on Eurema blanda Drury. Guangdong Forestry Science and Technology (广东林业科 技), (2): $33 \sim 38$ (in Chinese)

Huang B K (黄邦㑆), 2001. Fauna of Insect in Fujian Province of China (Vol.4). Fujian Science and Technology Press, Fuzhou (in Chinese)

Igarashi S, 2001. Life history of Teinopalpus aureus in Vietnam in comparison with that of T. imperialis. Butterflies, (30): $10 \sim 21$

Ma K M (马克明)，H M Kong (孔红梅)，W B Guang (关文 彬) and B J Fu (傅伯杰), 2001. Ecosystem health assessment: methods and directions. Acta Ecologica Sinca (生态学报)，21(12):2106 2116 (in Chinese)

SSC/IUCN, 1994. IUCN Red list Catagories. IUCN, Galand, Switzerland

WCMC, 1994. IUCN Red List of Threatened Animals. IUCN, Gland, Switzerland

Wen L Z (文礼章), 1998. Principle and Utilization of Entomology of Edible Insects. Hunan Science and Technology Press, Changsha (in Chinese)

World Resources Institute, The World Conservation Union and United Nations Environment Programme, 1993. Global Biodiversity Strategy. China Standard Press, Beijing

Wu Y (吴云), 1999. The Appreciation of World Famous Butterflies. Yunnan Education Publishing House, Kunming ( in Chinese)

Xie Y (解炎) and S Wang (汪松), 1995. IUCN Red List Categories. Chinese Biodiversity (生物多样性), 3(4)：234 239 (in Chinese)

Yuan D C (袁德成)，2001. Insect endangerment categories and protection grades. Entomological Knowledge (昆虫知识), 38(5) : $4 \sim 7$ (in Chinese)

You M S (尤民生), 1997. Conservation and utilization of the insect diversity in China. Chinese Biodiversity (生物多样 性), 5(2) : 135 141 (in Chinese)

(责任编辑：时意专) 